\title{
Plectanocotyle major sp. n. (Monogenea: Plectanocotylidae), a gill parasite of Chelidonichthys obscurus (Teleostei: Triglidae) from the Mediterranean Sea
}

\author{
Lobna Boudaya $^{1}$, Lassad Neifar $^{1}$ and Louis Euzet ${ }^{2}$ \\ ${ }^{1}$ Laboratoire de Bioécologie Animale, Département des Sciences de la Vie, Faculté des Sciences de Sfax, BP 802, 3038, Sfax, \\ Tunisie; \\ ${ }^{2}$ Station Méditerranéenne de l'Environnement Littoral, 1, Quai de la Daurade, F-34200 Sète, France
}

Key words: Monogenea, Plectanocotylidae, Plectanocotyle major, Chelidonichthys obscurus, Teleostei, Triglidae, Mediterranean Sea

\begin{abstract}
Plectanocotyle major sp. n. (Monogenea: Polyopisthocotylea: Plectanocotylidae) is described from Chelidonichthys obscurus (Bloch et Schneider, 1801) collected from the Mediterranean coasts (Tunisia and France). The new species is compared to Plectanocotyle gurnardi collected on Chelidonichthys gurnardus and the only other valid species in the genus Plectanocotyle. The new species differs from $P$. gurnardi by the clamp size $(137 \mu \mathrm{m} v s 64 \mu \mathrm{m}$ for clamp length and $110 \mu \mathrm{m} v s 60 \mu \mathrm{m}$ for clamp width, respectively) and the length of the male copulatory organ $(107 \mu \mathrm{m} v s 144 \mu \mathrm{m}$, respectively). Species of the Plectanocotylidae seem to be characterized by an oioxenic specificity.
\end{abstract}

Two species of Plectanocotylidae Poche, 1925, Plectanocotylinae Monticelli, 1903 (Monogenea, Polyopisthocotylea) are known from Mediterranean searobins (Triglidae): Plectanocotyle lorenzii Monticelli, 1899 and Triglicola obscurum (Euzet et Suriano, 1974). These two genera can be distinguished by the number of clamps on the haptor, three pairs for Plectanocotyle Diesing, 1830 and four pairs for Triglicola Mamaev et Paruchin, 1972. Plectanocotyle lorenzii was synonymised with Plectanocotyle gurnardi (Van Beneden et Hesse, 1863) by Llewellyn (1941). This synonymy remains hypothetical because the original description of P. lorenzii Monticelli, 1899, as well as the redescription by Palombi (1949), remain incomplete. In addition, the host (Trigla species) is unknown. The presence of Plectanocotyle gurnardi on Chelidonichthys gurnardus (Linnaeus, 1758) in the Mediterranean Sea must be checked and this monogenean redescribed.

In a recent study of the biology of Triglidae in Tunisian waters, we found on the gills of Chelidonichthys obscurus (Bloch et Schneider, 1801) two species of Plectanocotylinae: Triglicola obscurum and another species belonging to Plectanocotyle that we considered as a new species. We also found this species in the collection of one of us (L. E.) collected at Sète in 1969, 1970 and 2003. This species is compared to $P$. gurnardi collected at Sfax (Tunisia) and Sète (France) on the type-host, C. gurnardus. This new species is described herein.

\section{MATERIALS AND METHODS}

Specimens of Chelidonichthys obscurus and Chelidonichthys gurnardus caught by trawler were examined shortly after being landed. Gills were removed and placed in separate Petri dishes containing seawater, and examined for parasites using a stereomicroscope with incident light. Monogeneans were detached from the gills using a strong water current and transferred to a dish containing seawater. Some living parasites were studied, partially compressed beneath a coverslip, using a photonic microscope. Other specimens were transferred individually on a slide in a drop of ammonium picrate-glycerine after Malmberg (1957). The preparation was then covered with a round coverslip and sealed with Canada balsam. Some parasites, fixed in 70\% ethanol, were stained with Semichon's acetic carmine and following dehydration through a graded ethanol series, and then were cleared in clove oil and mounted in Canada balsam. Some specimens mounted in Berlèse medium were used to study the morphology of the haptoral clamps and copulatory complex.

Illustrations and measurements were made with the aid of a Leitz microscope with drawing tube. All measurements are given in micrometres. Ranges are given in the text followed in parentheses by the mean, standard deviation, and number of observations (n). Drawings (Figs. 2-6) were scanned and redrawn on a computer with CorelDRAW.

After Llewellyn (1956), the following appellation for clamp skeleton, is used: $a=$ median sclerite; $b=$ anterior marginal sclerite; $\mathrm{c}=$ dorsal posterior, marginal sclerite; $\mathrm{d}=$ ventral posterior, marginal sclerite; $\mathrm{e}=$ median posterior plate (Fig. 2). Host identification and nomenclature follow Froese and Pauly (2005). 


\section{RESULTS}

Family: P le ct a n o c ot y 1 id a e Poche, 1925 Subfamily: Plectanocotylinae Monticelli, 1903

\section{Plectanocotyle major sp. $\mathrm{n}$.}

Figs. 1-6

Description (based on 25 adult specimens). Body flattened dorsoventrally. Total length, including haptor, $1,500-2,300(1,841 \pm 148, \mathrm{n}=11)$; maximum width 210-600 $(442 \pm 83, \mathrm{n}=11)$ at level of ovary (Fig. 1). Haptor symmetrical, with three pairs of pedunculate clamps. Clamps 90-160 (137 $\pm 17, \mathrm{n}=17)$ long, 85$140(110 \pm 14, \mathrm{n}=17)$ wide (Figs. 2, 3). Clamp sclerite dimensions: a: 75-90 $(80 \pm 3, \mathrm{n}=21)$; b: 140-180 (157 $\pm 7, \mathrm{n}=21)$; c: $65-90(72 \pm 4, \mathrm{n}=21)$; : 55-70 $(67 \pm 7$, $\mathrm{n}=21)$; e: $25-40(33 \pm 3, \mathrm{n}=21)$ long, 60-80 (68 \pm 3 , $\mathrm{n}=21$ ) wide (Fig. 2). Terminal lappet present, 40-80 $(56 \pm 6, \mathrm{n}=13)$ long, $30-50(42 \pm 4, \mathrm{n}=13)$ wide, with two pairs of hamuli and one pair of uncinuli at posterior extremity. On each side, median hamulus 25-40 (32.5 \pm $2, \mathrm{n}=16$ ) long, with blade, ventral point, little guard and shaft with dorsal acute end; lateral hamulus 30-35 ( $33 \pm 2, \mathrm{n}=16)$ long, with shaft, guard, blade and ventral point; postero-lateral uncinulus $10-15(12 \pm 1, \mathrm{n}=$ 13) long, between hamuli (Fig. 4). Four to five tegumental strips on each side of anterior jaw.

Mouth subterminal, ventral. Two hemispherical buccal suckers, 40-60 $(48 \pm 4, \mathrm{n}=22)$ in diameter. Median pharynx, small, 30-70 $(45 \pm 3, \mathrm{n}=24)$ in diameter. Short oesophagus present. Intestine bifurcate, branches with medial and lateral caeca, extending into posterior region of the haptor, not confluent posteriorly. Ocellar granules absent.

Testes 19-22 $(21 \pm 1, \mathrm{n}=11)$ in number, in two irregular columns. Testes 30-70 $(57 \pm 8, \mathrm{n}=30)$ long, 50-90 $(76 \pm 9, \mathrm{n}=30)$ wide. Vas deferens median, dorsal. Common genital pore median at level of intestinal bifurcation. Male copulatory organ with 10 long, slender sclerites. Two medians pin-shaped with spherical head 85-110 $(102 \pm 4, \mathrm{n}=21)$ long, surrounded on each side by four simple sclerites $90-120(107 \pm 6, \mathrm{n}=25)$ long (Fig. 6). Male accessory glands and two correspondent reservoirs one on each side of median male sclerites as described in Triglicola obscurum by Euzet and Suriano (1974).

Ovary tubular, turned back on itself in mid-region of body, with oviduct directed anteriorly. Ootype on left side of ovary. Irregular vitelline follicles well developed on each side of the body, from level of oesophagus to central part of haptor. No vagina observed. Uterus ventral, median. Eggs 120-185 (146 $\pm 5, \mathrm{n}=25)$ long, 40$85(57 \pm 5, \mathrm{n}=25)$ wide, with posterior (proximal) polar filament 150-230 (200 $\pm 28, \mathrm{n}=6)$ long (Fig. 5).

$\mathrm{T}$ y $\mathrm{p}$ e $\mathrm{h}$ o s $\mathrm{t}$ : Chelidonichthys obscurus (Bloch et Schneider, 1801) (Triglidae, Scorpaeniformes).

T y p e 1 o c a lity: Sète (France) $\left(43^{\circ} 02^{\prime} \mathrm{N}, 3^{\circ} 48^{\prime} \mathrm{E}\right)$.

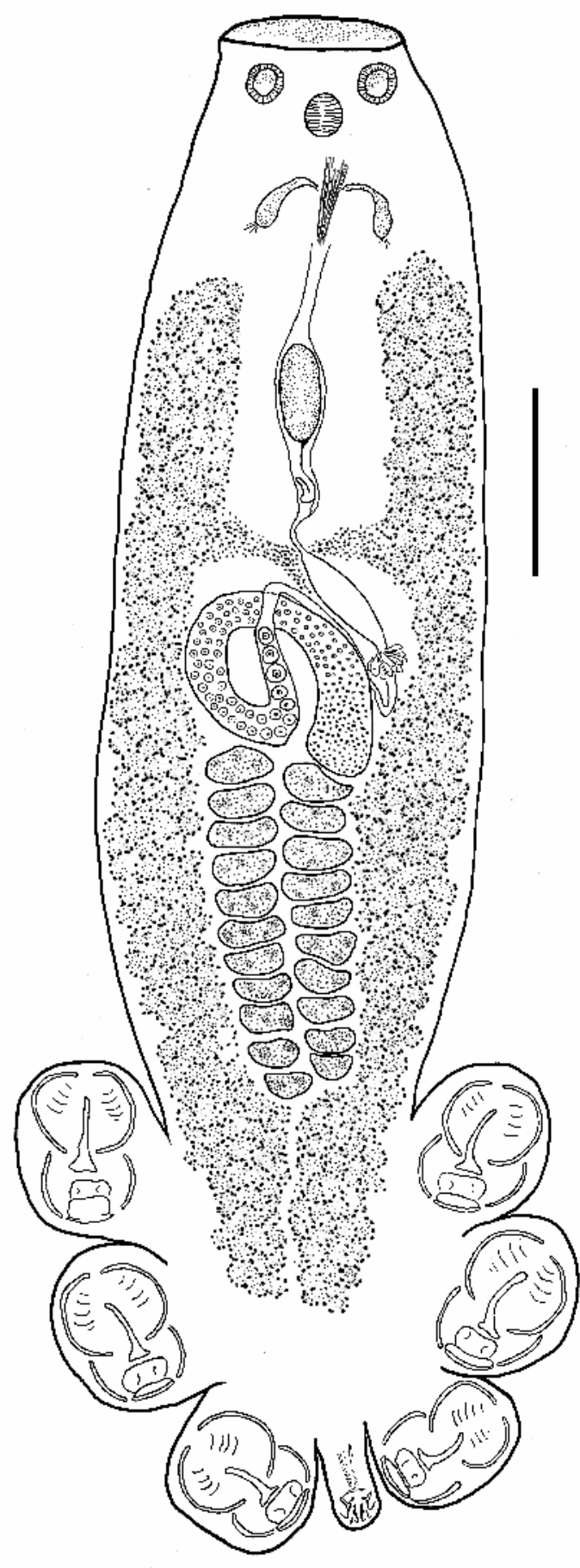

Fig. 1. Plectanocotyle major $\mathrm{sp}$. n. from Chelidonichthys obscurus. Adult in toto, ventral view (composite drawing). Scale bar $=200 \mu \mathrm{m}$.

O the r 1 o c a 1 i t i e s : Sfax (Tunisia) $\left(37^{\circ} 30^{\prime} \mathrm{N}, 9^{\circ} 50^{\prime} \mathrm{E}\right)$; Mahdia (Tunisia) $\left(33^{\circ} 15^{\prime} \mathrm{N}, 11^{\circ} 10^{\prime} \mathrm{E}\right)$.

Microhabitat: Gills.

Prevale n c e : $80 \%$ (examined 46, infected 37 ).

$\mathrm{T}$ y $\mathrm{p}$ e $\mathrm{m}$ a t e r i a 1: Holotype in Muséum National d'Histoire Naturelle, Paris, MNHN 267 HG No. Tj146 

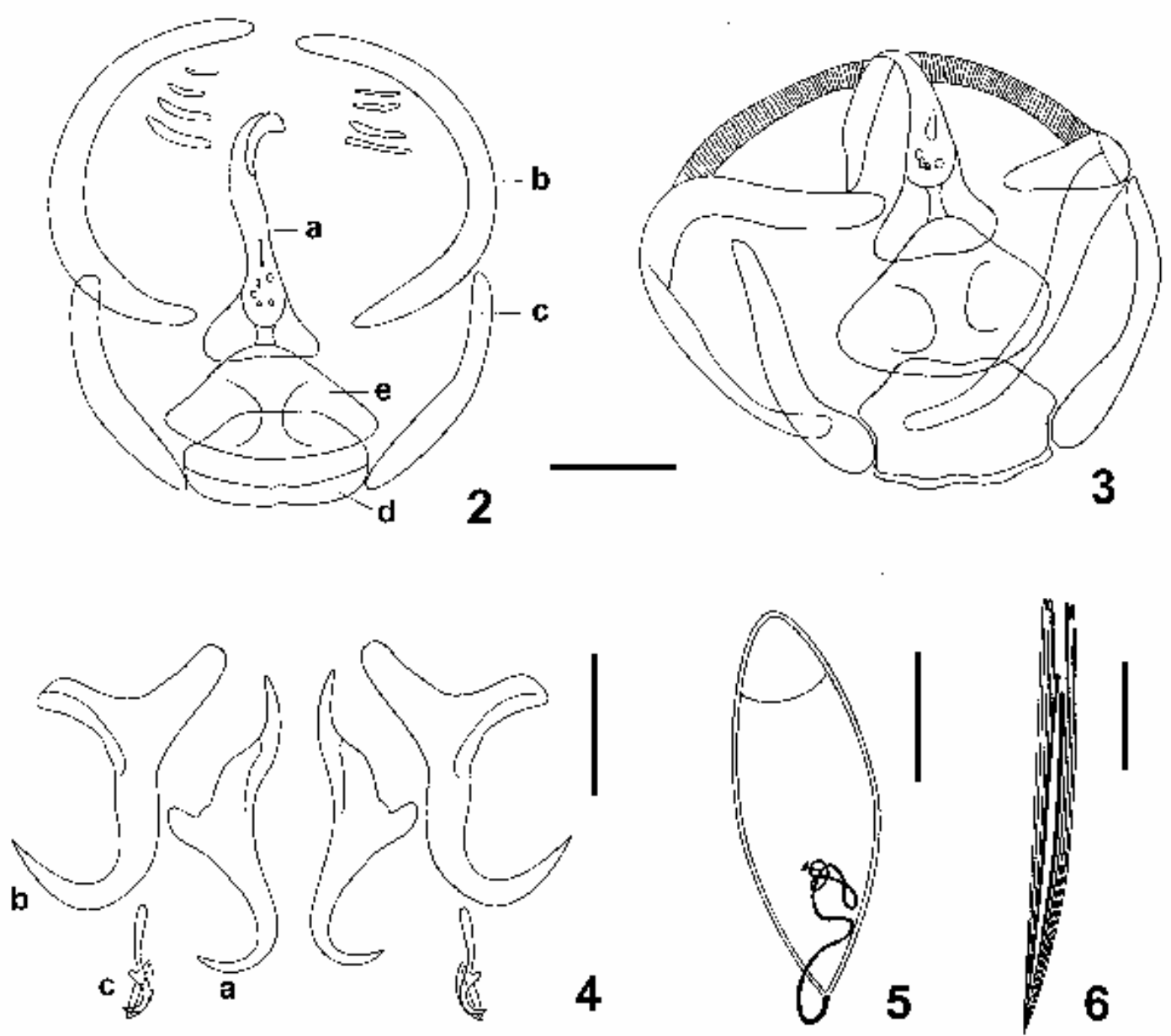

Figs. 2-6. Plectanocotyle major sp. n. from Chelidonichthys obscurus. Fig. 2. Clamp unfolded. Abbreviations: a - median sclerite, $\mathrm{b}$ - anterior marginal sclerite, $\mathrm{c}$ - dorsal posterior, marginal sclerite, $\mathrm{d}$ - ventral posterior, marginal sclerite, $\mathrm{e}-$ median posterior plate. Fig. 3. Clamp folded. Fig. 4. Sclerites of terminal lappet. Abbreviations: a - median hamulus, b - lateral hamulus, $\mathrm{c}$ - postero-lateral uncinulus. Fig. 5. Egg. Fig. 6. Male copulatory organ. Scale bars: Figs. 2, 3, $5=50 \mu \mathrm{m}$; Figs. 4, $6=25 \mu \mathrm{m}$.

and 5 paratypes MNHN 268 HG No. Tj147, MNHN 269 HG No. Tj148, MNHN 270 HG No. Tj149, MNHN 271 HG No. Tj149bis, MNHN 272 HG No. Tj150. Three paratypes in the Natural History Museum, London, BMNH 2005. 5.18.1-4. Three paratypes in the Institute of Parasitology, Academy of Sciences of the Czech Republic, České Budějovice (Coll. No. M-413). Other paratypes in collection of the senior author.

E t y m o log y: The specific epithet major refers to the large size of the clamps of specimens collected, compared with the only other described species, Plectanocotyle gurnardi.

\section{DISCUSSION}

Plectanocotyle major can be distinguished from $P$. gurnardi (Van Beneden et Hesse, 1863), collected on Chelidonichthys gurnardus from Sète, by the size of the clamps $(137 \pm 17$ vs $64 \pm 4$ for the length, respectively and $110 \pm 14$ vs $60 \pm 4$ for the width, respectively) and the size of the male copulatory organ $(107 \pm 6$ vs $144 \pm$
8 respectively). The clamps of $P$. major are often unfolded (Fig. 2) and study of the sclerites is easy. Clamps of $P$. gurnardi are rarely unfolded and more difficult to analyse. However, comparison shows that they have a similar structure as detailed by Llewellyn (1956) and Euzet and Suriano (1974). The assemblage of the sclerites in the male copulatory organ of $P$. major and $P$. gurnardi is similar to that described by Euzet and Suriano (1974) on Triglicola obscurum with two short sclerites each surrounded by four long sclerites.

Plectanocotyle major coexists with Triglicola obscurum on the gills of Chelidonichthys obscurus from Sète and Sfax. Our data show that Plectanocotyle major occupies the base of the gill filament whereas T. obscurum is located at the distal end of the gill filament. The presence of an additional pair of clamps on T. obscurum probably ensures better adhesion of this parasite, which is subjected to a greater water flow at the filament ends. 
The absence of a vagina and the presence of a genital apparatus composed of a bundle of long spines in Plectanocotyle suggest the possibility of traumatic copulation and fertilisation as is known to occur in Diclidophora (see Frankland 1955). However, in contrast with Diclidophora, no seminal receptacle usually associated with this mode of copulation was observed in Plectanocotyle.

The presence of Plectanocotyle gurnardi on Chelidonichthys gurnardus and P. major on Chelidonichthys obscurus support the oioxenic specificity of Plectanocotylinae. However, P. gurnardi is reported by Llewellyn (1941), Sproston (1946) and Llewellyn et al. (1984) from three other species of Triglidae, Aspitrigla cuculus (Linnaeus, 1758), Trigla lineata Gmelin, 1787 [=Chelidonichthys lastoviza (Bonnaterre, 1788)], and Trigla lucerna (Linnaeus, 1758) [= Chelidonichthys lucernus (Linnaeus, 1758)]. During our study, we col- lected a small number of Plectanocotyle from $\mathrm{A}$. сисиlus and T. lineata, but these parasites seem to be different from all the described species. More specimens must be collected and then the specific identity verified. For T. lucerna, 55 specimens were examined in Sfax and Sète and no Plectanocotyle was collected.

Jovelin and Justine (2001) in their study on the phylogenetic relations of the Polyopisthocotylea showed that Plectanocotylidae represent a monophyletic group. The three species analysed, Plectanocotyle gurnardi, Plectanocotyle sp. (from $T$. lineata - as C. lastoviza) and Triglicola obscurum, were genetically different.

Acknowledgements. We thank Prof. A. Bouain for invaluable support and Dr. Isaure and Vincent Connors for revision of the English in this manuscript. We also wish to thank two anonymous reviewers for their helpful comments.

\section{REFERENCES}

EUZET L., SURIANO D.M. 1974: Plectanocotyloides obscurum n. g., n. sp. (Monogenea) parasite branchial d'Aspitrigla obscura (Téléostéen) en Méditerranée. Bull. Mus. Natl. Hist. Nat. Paris, $3^{\mathrm{e}}$ Sér. 137 (1973), Zoologie 101: 807-813.

FRANKLAND H.M.T. 1955: The life history and bionomics of Diclidophora denticulata (Trematoda, Monogenea). Parasitology 45: 313-351.

FROESE R., PAULY D. 2005: FishBase. World Wide Web electronic publication. www.fishbase.org, version 01 , 2005.

JOVELIN R., JUSTINE J.-L. 2001: Phylogenetic relationships within the polyopisthocotylean monogeneans (Platyhelminthes) inferred from partial $28 \mathrm{~S}$ rDNA sequences. Int. J. Parasitol. 31: 393-401.

LLEWELLYN J. 1941: The taxonomy of the monogenetic trematode Plectanocotyle gurnardi (v. Ben. \& Hesse). Parasitology 33: 431-432.
LLEWELLYN J. 1956: The adhesive mechanisms of monogenetic trematodes: the attachment of Plectanocotyle gurnardi (v. Beneden et Hesse) to the gills of Trigla. J. Mar. Biol. Assoc. U.K. 39: 561-589.

LLEWELLYN J., GREEN J.E., KEARN G.C. 1984: A checklist of Monogenean (Platyhelminth) parasites of Plymouth hosts. J. Mar. Biol. Assoc. U.K. 64: 881-887.

MALMBERG G. 1957: [On the occurrence of Gyrodactylus on Swedish fishes.] Skrifter Utgivna av Sodra Sveriges Fiskeriforening (1956), 19-76. (In Swedish, with description of species and a summary in English.)

PALOMBI A. 1949: I trematodi d'Italia. Parte I. Trematodi monogenetici. Arch. Zool. Ital. 34: 203-408.

SPROSTON N.G. 1946: A synopsis of the monogenetic trematodes. Trans. Zool. Soc. Lond. 25: 185-600. 